\title{
Identification of PPARy Agonists from Natural Sources Using Different In Silico Approaches
}

Authors

Affiliations
Rime B. El-Houri ${ }^{1}$, Jérémie Mortier ${ }^{2}$, Manuela S. Murgueitioº ${ }^{2}$, Gerhard Wolber ${ }^{2}$, Lars P. Christensen ${ }^{1}$

${ }^{1}$ Department of Chemical Engineering, Biotechnology and Environmental Technology, University of Southern Denmark, Odense, Denmark

${ }^{2}$ Computer-Aided Drug Design, Institute of Pharmacy, Medicinal and Pharmaceutical Chemistry, Freie Universität Berlin, Berlin, Germany

\section{Key words \\ - PPARY \\ - natural products \\ - 3D pharmacophores \\ - in silico screening \\ - molecular docking}

received July 9, 2014

revised August 27, 2014

accepted August 28, 2014

Bibliography

DOI http://dx.doi.org/

10.1055/s-0034-1383119

Published online September 24, 2014

Planta Med 2015; 81: 488-494

(c) Georg Thieme Verlag KG

Stuttgart · New York .

ISSN 0032-0943

Correspondence

Prof. Dr. Lars P. Christensen

Department of Chemical

Engineering

Biotechnology and Environ-

mental Technology

University of Southern Denmark

Campusvej 55

5230 Odense $\mathrm{M}$

Denmark

Phone: + 4565507361

Fax: +4565507354

Ipc@kbm.sdu.dk

\section{Abstract}

$\nabla$

Peroxisome proliferator-activated receptor $\gamma$ plays an important role in lipid and glucose homeostasis and is the target of many drug discovery investigations because of its role in diseases such as type 2 diabetes. Activation of peroxisome proliferator-activated receptor $\gamma$ by agonists leads to a conformational change in the ligand-binding domain altering the transcription of several target genes involved in glucose and lipid metabolism, resulting in, for example, facilitation of glucose and lipid uptake and amelioration of insulin resistance, and other effects that are important in the treatment of type 2 diabetes. Peroxisome proliferator-activated receptor $\gamma$ partial agonists are compounds with diminished agonist efficacy compared to full agonists; however, they maintain the antidiabetic effect of full agonists but do not induce the same magnitude of side effects. This mini-review gives a short introduction to in silico screening methods and recent research ad-

\section{Introduction}

$\nabla$

Natural products have been and continue to be rich sources for drug discovery. Today over $60 \%$ of the drugs that are on the market derive from natural sources [1,2]. Peroxisome proliferator-activated receptor $\gamma$ (PPAR $\gamma$ ) plays an essential role in lipid and glucose homeostasis and is the target for many drug discovery efforts because of its role in diseases, such as T2D [3-5]. Obesity-linked phosphorylation of PPAR $\gamma$ by the protein kinase Cdk5 seems to be involved in the pathogenesis of insulin resistance, and thus the development of T2D. Blocking the phosphorylation by PPAR $\gamma$ ligands (agonists) can restore a more normal nondiabetic pattern of gene expression [6]. The TZDs, a class of synthetic insulin-sensitizing drugs, target and activate PPAR $\gamma$. Activation of PPAR $\gamma$ by vances using computational approaches to identify peroxisome proliferator-activated receptor $\gamma$ agonists, especially partial agonists, from natural sources and how these ligands bind to the peroxisome proliferator-activated receptor $\gamma$ in order to better understand their biological effects.

\section{Abbreviations}

$\nabla$

Cdk5: $\quad$ cyclin-dependent kinase 5

H3: Helix H3

H12: Helix H12

LBD: $\quad$ ligand-binding domain

LBP: ligand-binding pocket

PDB: $\quad$ protein data bank

PPAR: peroxisome proliferator-activated receptor

TZD: thiazolidinedione

T2D: $\quad$ type 2 diabetes

VS: virtual screening

agonists, such as TZDs, leads to a conformational change in the LBD altering the transcription of several target genes involved in glucose and lipid metabolism, resulting in, for example, the facilitation of glucose and lipid uptake, stimulation of glucose oxidation, a decrease in free fatty acid levels, and the amelioration of insulin resistance [35]. Administration of TZDs can cause severe side effects, which have been linked to their behavior as full agonists of PPAR $\gamma$ [7]. PPAR $\gamma$ partial agonists are compounds with diminished agonist efficacy that maintain the antidiabetic effect of full agonists but usually do not induce the same magnitude of side effects [8]. The different pharmacology properties of full and partial agonists indicate that changes in the ligand-receptor interaction are responsible for these differences. 
A wide variety of promising PPAR $\gamma$ partial agonists of plant origin have been identified using a bioassay-guided approach. Bioassayguided fractionation is a very efficient method for the discovery of natural products with interesting bioactivities from natural sources, but it is a tedious process involving time-consuming separation steps combined with biological test models in vitro and/ or in vivo. In recent years, the field of computational techniques has been evolving towards applying in silico VS to support the research in drug discovery, design, development, and optimization [9-11].

In silico screening has been established as one of the most important computational techniques used for prioritizing compounds to be selected for experimental testing. This mini-review gives a short introduction to in silico screening methods and provides an assessment of the current state-of-the-art computational approaches to identify PPARr agonists, especially partial agonists, from natural sources and discusses how these ligands can bind to PPAR $\gamma$ in order to better understand their biological effects.

\section{The Complexity of Natural Products with Respect to Molecular Modelling \\ $\nabla$}

Natural products have several advantages, but also challenges, when viewed from the perspective of a medicinal chemist. Undoubtedly, they show high diversity, bioavailability, and contain bio-privileged structures [12]. However, to work with natural products in biochemical assays, they have to be isolated from multicomponent mixtures using complex separation procedures requiring expertise in phytochemistry and analytical chemistry. Furthermore, natural products show higher chemical complexity than classical "drug-like" molecules, including higher flexibility, a higher number of ketones and hydroxyl groups, and often a large number of chiral centers $[13,14]$. This complexity results in further challenges for computational chemistry and in silico VS, especially in terms of handling stereochemistry in the correct way and in covering conformational space when dealing with highly flexible molecules.

\section{Computer-assisted Drug Design and Virtual Screening $\nabla$}

In order to deal with the high experimental effort in isolating and testing natural products, in silico VS methods have become a successful technique to enhance experimental success rates by prioritizing those natural products that show a high probability to bind to a specific target. Plant extracts containing several potential bioactive natural products can thus be prioritized for testing according to computational predictions for each contained constituent. Subsequent separation is only performed if the extract shows biological activity and the high efforts of separation [15] can be guided by the hypotheses generated in silico [16].

Several computer-aided methods exist for VS, which can roughly be divided into structure- and ligand-based methods. Structurebased modelling relies on the availability of an experimentally determined structure of the macromolecular target under investigation. The Protein Data Bank (PDB) $[17,18]$ represents the largest public repository of protein and nucleic acid structures determined by X-ray crystallography or NMR and currently comprise more than a hundred thousand macromolecular structures, many of them with co-crystallized ligands.
Table 1 The most important programs and algorithms used for docking.

\begin{tabular}{lll} 
Program & Algorithm & Ref. \\
AutoDock & Lamarckian Genetic Algorithm & {$[64]$} \\
\hline DOCK & Volume- or shape-based algorithm & {$[65]$} \\
FlexX & $\begin{array}{l}\text { Incremental ligand fragmentation and } \\
\text { reconstruction }\end{array}$ & {$[66]$} \\
& Systematic search & {$[67]$} \\
Glide & Genetic algorithm & {$[68]$} \\
LOLD & Monte Carlo approaches & {$[69]$} \\
ParaDOCKs & Particle swarm optimization and other & {$[70]$} \\
& metaheuristics & \\
Surflex & Surface-based molecular similarity methods & {$[71]$}
\end{tabular}

The most popular structure-based approaches are docking and structure-based 3D pharmacophores. While docking flexibly fits a ligand into a protein-binding site [19-22], structure-based 3D pharmacophores describe protein-ligand interactions by an ensemble of chemical features that can then be used for VS [23]. When employed for the VS of large molecule databases, docking suffers from a high false positive rate, which is mainly caused by problems in scoring [24-26]. Nevertheless, docking remains the method of choice when investigating a binding mode and generating ideas for further lead optimization [27]. The most important docking methods are summarized in 0 Table 1. Structurebased 3D pharmacophores can be optimized to contain those chemical features that are known to be important for binding and can thus, if developed carefully, represent predictive VS filters [28].

Despite recent advances in protein crystallization, especially with respect to membrane-bound proteins [29], not all relevant macromolecular targets [30] can be crystallized. In those cases, ligand-based methods are used to overcome this limitation. Based on the hypothesis that different ligands bind at the pocket in a similar manner, a similarity search with respect to known active compounds can be performed. In case of a ligand-based pharmacophore, common chemical features are derived using a 3D overlay [31]. More simple approaches use steric similarity to the most active ligand to perform VS [26,32].

However, further research into lesser-understood biochemical processes is necessary to improve the reliability of VS as a standalone process for identifying bioactive constituents. These processes include protein flexibility and induced-fit adaptations, the role of water in solvation, desolvation, and ligand binding, the involvement of electrostatics, as well as the stereochemistry and conformational space of the ligands [18,33]. Another factor that can limit VS productivity is the amount of information available when building a compound library. Although a huge amount of information is available when considering natural products for the treatment and prevention of diseases, they do not include all potential bioactive natural products. Finally, VS also has its limitation when considering the concentration needed for a ligand to elicit its therapeutic effect. Docking predicts ligands that may elicit the desired activity, but bioassays are needed to further refine the group of viable candidates to a selected group of hits that at a specific concentration will activate the protein, e.g., PPAR However, as mentioned in the introduction and in the beginning of this section, VS can be useful after the fractionation of extracts and structural elucidation of major components in the fractions to aid in identifying which constituents are potential bioactive compounds, such as PPARr partial agonists. 
Peroxisome Proliferator-Activated Receptor $y$ As a Target Protein

$\nabla$

PPAR $\gamma$ exist as two isoforms, PPAR $\gamma 1$ and PPAR $\gamma 2$, which are expressed in many tissues. In humans, both PPAR 1 and $\gamma 2$ are abundant in adipose tissue but are, for example, present at low levels in skeletal muscle [34]. In order to understand the binding mode of ligands toward PPAR $\gamma$, currently, 124 crystal structures of PPARy LBD are available of which 109 contain co-crystallized ligands [17]. The binding mode of partial agonists to PPAR $\gamma$ has been intensively studied revealing different binding modes, which allowed for a more detailed investigation and subsequent identification of potent PPAR $\gamma$ partial agonists [35-38].

Investigation of several known crystallographic structures of the PPARY LBD bound to an agonist revealed two binding modes in the same LBD, which correspond to full and partial agonists [39]. The LBP of the PPAR $\gamma$ LBD is a large Y-shaped ligand-binding cavity, consisting of an entrance (arm III) that branches off into two binding pockets (arm I and arm II). Arm I is extended toward helix H12 (H12) and arm II is situated between helix H3 (H3) and the $\beta$-sheet ( $\odot$ Fig. 1). Arm I is the only substantially polar cavity of the PPAR $\gamma$ LBD, whereas arm II and the interior of arm III are mainly hydrophobic [40]. Full agonists occupy arm I forming a network of hydrogen bonds with the side chains of amino acids Ser289, His323, His449, and Tyr473. These interactions stabilize $\mathrm{H} 12$ and are mainly responsible for the transactivation activity of PPARy. In addition, full agonists also occupy arm II through a hydrophobic tail $[41,42]$. On the other hand, the partial agonists interact mainly with amino residues on regions other than $\mathrm{H} 12$ through a hydrogen bond with Ser342 of arm III, but also with arm II through several hydrophobic contacts $[35,36]$. This binding mode causes a lower degree of $\mathrm{H} 12$ stabilization and an increase in the stabilization of $\mathrm{H} 3$ that affects the recruitment of coactivators and decreases the transactivation activity of PPAR $\gamma[43$, 44].

Although co-crystal structures of the PPAR $\gamma$ LBD bound to ligands give information on atomic differences in the LBD, it provides little insight into the graded activity of the ligands and therefore does not explain why agonists with different PPAR $\gamma$ transactivation activities show similar insulin-sensitizing potencies. However, recent studies have demonstrated that the antidiabetic efficacy of different ligands correlates with the ligand-binding affinity as well as their ability to inhibit phosphorylation of PPAR $\gamma$ by Cdk5 at Ser273 in PPAR 2 and Ser245 in PPAR 1 , thereby preventing the unregulated expression of some target genes involved in lipid and glucose homeostasis $[6,45,46]$. Furthermore, the potency of blockage of Ser273/Ser245 phosphorylation by ligands appears to be associated with the strength of interaction with the backbone amide at Ser342 (graded PPAR $r$ agonism) and seems not to depend on the degree of classical agonist action of full agonists by stabilizing H12 $[45,46]$. A substantial part of the antidiabetic effect of full and partial agonists of PPAR $\gamma$ may therefore be explained by the inhibition of PPAR phosphorylation. The side effects of full agonists are therefore likely to occur through the classical agonist action. Thus, an effective partial agonist of PPAR $r$ with reduced side effects should then have a weak transactivation activity, but a high phosphorylation inhibitory activity on PPARy at Ser273/Ser245 $[45,46]$. Finally, Hughes et al. [47] have recently demonstrated that synthetic ligands designed to mimic the activity of endogenous ligands (fatty acid derivatives) via binding to the canonical hydrophobic LBP of the PPAR $\gamma$ LBD are able to bind to an alternate site on the LBD. Alternate site

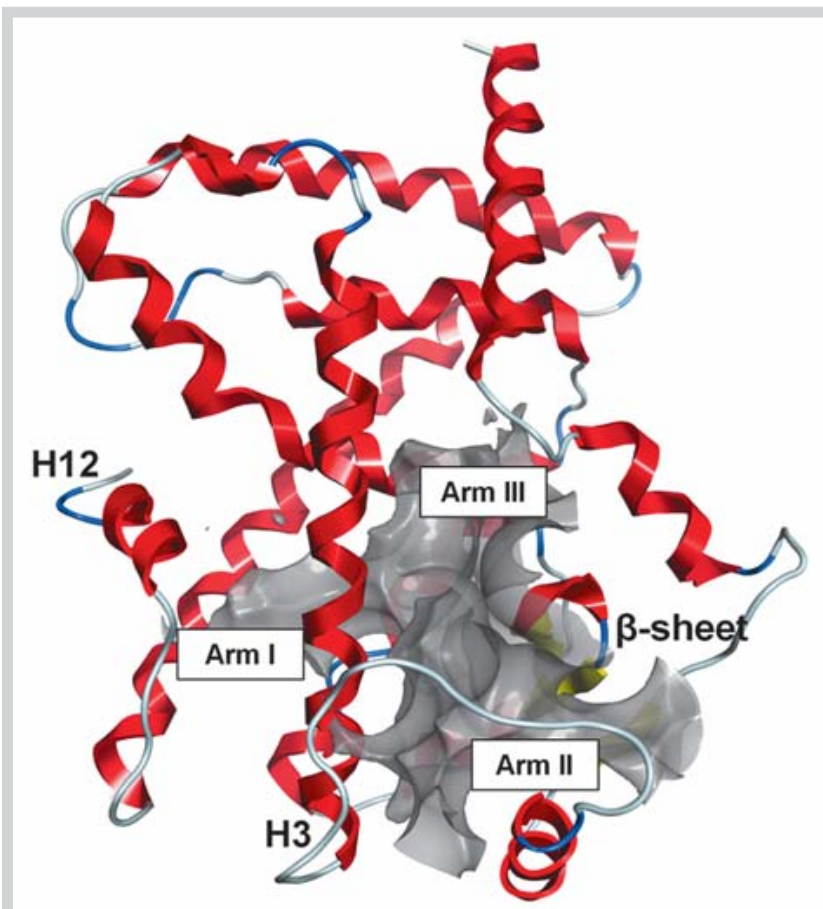

Fig. 1 3D structure of PPARy. The crystal structure of PPARy (PDB code: 2F4B [72]) is shown with $\alpha$-helices colored in red, $\beta$-sheets in yellow, and the ligand-binding site in grey. (Color figure available online only.)

binding affects the structure and function of PPAR $\gamma$, and hence may contribute to the pharmacological response of PPAR $r$ ligands. Alternate site binding can occur via the following three mechanisms of potential pharmacological relevance [47]: (1) binding of two molecules of the same ligand to PPAR $\gamma$, one to the canonical LBP and a second to the alternate binding site; (2) the canonical LBP is "blocked" by a covalently bound irreversible antagonist; and (3) the canonical LBP is covalently bound to an endogenous ligand. If, for example, the PPAR $\gamma$ LBD is occupied by a covalently bound endogenous ligand, such as a prostaglandin (e.g., 15-deoxy- $\Delta^{12,14}$-prostaglandin $\mathrm{J}_{2}$ ) or an oxidized fatty acid (e.g., 5-oxoeicosatetraenoic acid) $[48,49]$, as described in the latter mechanism, the alternate binding site could be a target for allosteric modulators [47].

The above-mentioned new findings have not yet been applied into in silico VS, but constitute very useful information for understanding the mechanism of ligand and receptor dynamics and thus the mechanism of action of full and partial agonists of PPAR . Finally, incorporation of this new knowledge in VS may be a stepping-stone for the identification of new and more efficient ligands for PPAR $\gamma$.

\section{Peroxisome Proliferator-Activated Receptor y Agonists From Natural Sources Discovered by Virtual Screening $\nabla$}

Considering that plants have a long history in the traditional treatment of diabetes [50], natural product libraries represent a very promising source of novel PPAR ligands. Natural sources that contain PPARr agonists have been described in a few reviews [51-53]. Although these reviews do not represent an exhaustive and updated source of information about natural sources for 
PPAR agonists, they contain useful information that may be helpful in building up natural product libraries to be used in VS. To date, several VS studies have been used successfully to identify PPAR $\gamma$ agonists, including partial agonists from botanical sources. The first VS of a natural product library to identify novel PPAR $\gamma$ agonists was performed by Salam et al. [54]. They used a structure-based docking method and screened an in-house natural product library consisting of 200 compounds extracted from botanical sources. The compounds were examined for their potential to engage several residues in a binding mode typical for PPAR agonists [40-42]. Their screening resulted in identifying several flavonoids, isoflavonoids, gingeroids, and ginkolides as potential PPAR full agonists, with flavonoids/isoflavonoids being the most promising. Flavonoids/isoflavonoids of particular interest were apigenin, chrysin, pseudobaptigenin, biochanin A, genistein, and hesperidin ( $\boldsymbol{O}$ Fig. 2 ). When tested in vitro for cellbased transcriptional factor activity, all compounds demonstrated significant activation of PPAR lected the flavanone naringenin ( $\boldsymbol{O}$ Fig. 2 ) among the best scoring docked compounds, which was later confirmed to activate PPAR $\gamma$ in vitro by Christensen et al. [55].

Using a structure-based pharmacophore screening of the AnalytiCon Discovery collection (Analyticon Discovery $\mathrm{GmbH}$ ) of natural products and derivatives, Tanrikulu et al. [56] were able to identify two semisynthetic derivatives of the sesquiterpene lactone $\alpha$-santonin ( $\alpha$-santonin-derivative 1 and $\alpha$-santonin-derivative 2; 0 Fig. 3) as potential PPAR $\gamma$ agonists. The testing of these compounds in a cellular reporter gene assay revealed that $\alpha$-santonin-derivative 1 activated PPAR $\gamma$ with $110 \%$ relatively to the PPAR $\gamma$ full agonist pioglitazone while it activated PPAR $\alpha$ with $16 \%$ relatively to the PPAR $\alpha$ agonist GW7647. This indicates that this compound acts as a PPAR $\alpha / \gamma$ dual agonist. In comparison, $\alpha$ santonin-derivative 2 only activated PPAR $\gamma$ with $33 \%$ relatively to pioglitazone without activation of PPAR $\alpha$, indicating that this compound is a selective PPAR $\gamma$ partial agonist. Docking of $\alpha$-santonin-derivative 1 into a PPAR $\gamma$ structure supported its function as a PPAR $\gamma$ full agonist as it formed hydrogen bonds to several residues, including Tyr473 [40-42].

In aiming to identify PPAR $\gamma$ partial agonists, several studies have been performed using pharmacophore-based VS on different natural product libraries (DIOS database [57], Chinese Herbal Medicine database [58], Chinese Herbal Constituents database [59], Natural product subset of the ZINC database [60], and inhouse natural products databases). Fakhrudin et al. [58] identified three neolignans (dieugenol, tetrahydrodieugenol, and magnolol; O Fig. 4) as PPARr partial agonists. The results were also confirmed by a PPAR luciferase reporter gene transactivation assay, as the maximal fold activation by all three compounds was several folds lower than the full agonist pioglitazone. The three compounds were docked into the X-ray structure of PPAR. X-ray crystallography experiments later confirmed the computationally predicted bivalent binding ( $\odot$ Fig. 5 ) and a conformation typical for partial agonists, including a hydrogen bond to the residue Ser342 [35,36]. Petersen et al. [61] identified oleanolic acid ( $\bigcirc$ Fig. 4), which also shows a binding mode different from full agonists.

Lately, Guasch et al. [62,63] performed a VS study to identify potential PPARr partial agonists in extracts with known antidiabetic activity. They developed a structure-based pharmacophore and anti-pharmacophore (i.e., a 3D interaction pattern that matches those molecules, which describes the binding to undesired PPAR $\gamma$ isoforms or binding modes) to identify potential PPAR $\gamma$ partial

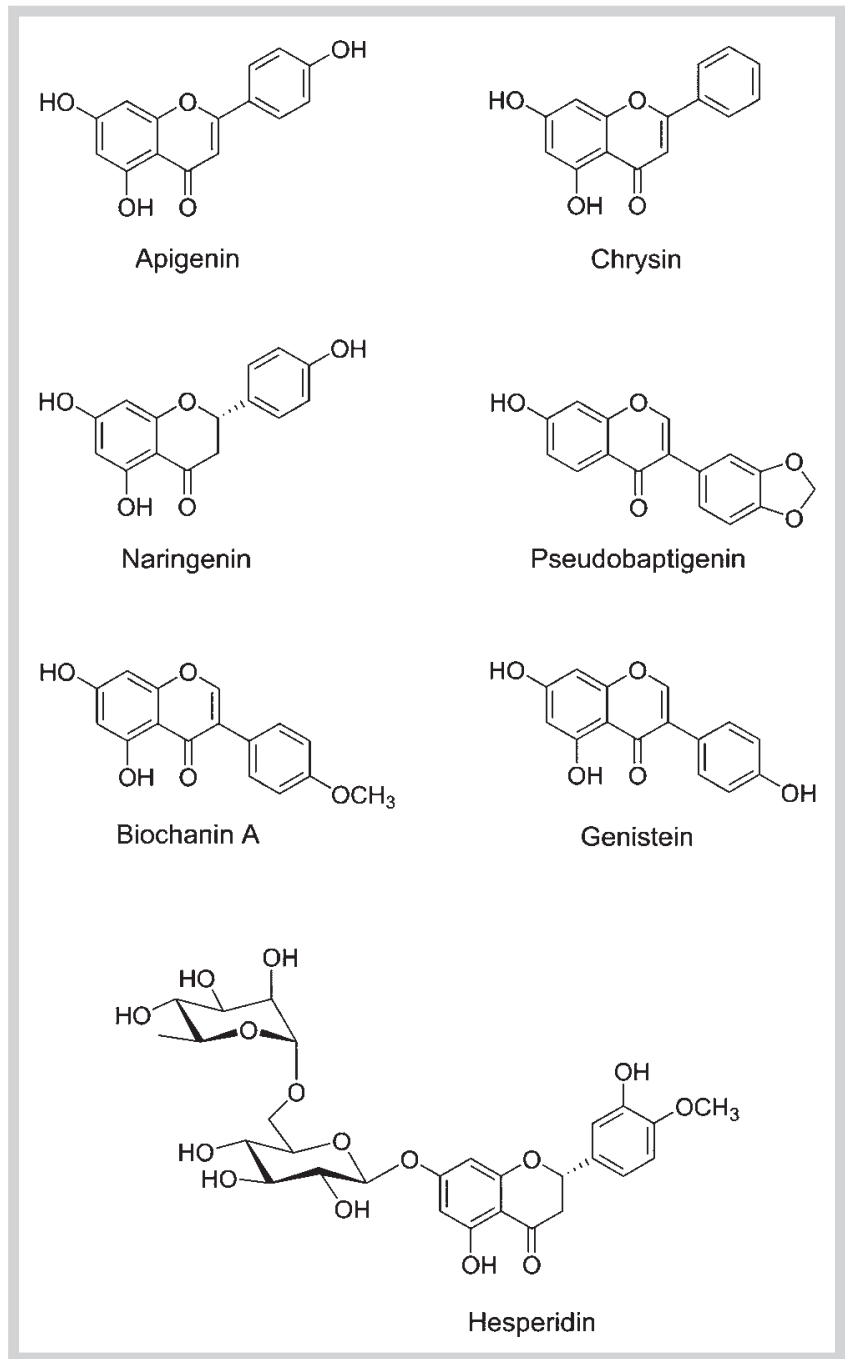

Fig. 2 Chemical structures of naturally occurring flavonoids (apigenin, chrysin, naringenin, hesperidin) and isoflavonoids (pseudobaptigenin, biochanin A, genistein) discovered by virtual screening as PPARY agonists.

agonists. The anti-pharmacophore was used to exclude possible full agonists because they present more clearly defined features than partial agonists. They applied their VS workflow to a group of PPAR $r$ partial agonists known from the literature and some decoys. Sixty-five compounds were predicted by the VS workflow to be potential PPARr partial agonists and have all been isolated from 74 natural sources. Among the identified compounds, some were found in extracts that exert antidiabetic activities while others were related to extracts never recorded for antidiabetic activity.

In silico screening has thus proven to be a highly effective enhancement to bioassay screening and thus renders the search for novel potential antidiabetic plant extracts and compounds faster and cheaper than the usual bioassay-guided approach.

\section{Conflict of Interest \\ $\nabla$}

The authors declare no conflict of interest. 
<smiles></smiles>

Pioglitazone<smiles>CCCOc1cc(C)c2c(c1C)C[C@H]([C@H](C)C(=O)O)CC2</smiles>

alpha-Santonin-derivative 1<smiles>CC(C)(Sc1ccc(CCN(CCCCC2CCCCC2)C(=O)NC2CCCCC2)cc1)C(=O)O</smiles>

GW7647<smiles>CCCOc1cc(C)c2c(c1C)C[C@H](C(=O)N1CCC(C(=O)O)CC1)CC2</smiles>

Fig. 3 Chemical structures of pioglitazone, GW7647, $\alpha$-santonin-derivative 1, and $\alpha$-santoninderivative 2 . Pioglitazone has one chiral center situated in the thiazolidinedione ring and the active substance is an equimolar mixture of the $(R)$ - and (S)-enantiomers of pioglitazone (racemic mixture) [73].

alpha-Santonin-derivative 2<smiles>C=CCc1cc(CC=C)c(O)c(-c2cc(CC=C)cc(OC)c2O)c1</smiles>

Dieugenol<smiles>C=CCc1ccc(O)c(-c2cc(CC=C)ccc2O)c1</smiles>

Magnolol<smiles>CCCc1cc(OC)c(O)c(-c2cc(CCC)cc(OC)c2O)c1</smiles>

Tetrahydrodieugenol<smiles>CC1(C)CCC2(C(=O)O)CCC3C(=CCC4[C@@]3(C)CCC3C(C)(C)[C@@H](O)CC[C@@]34C)C2C1</smiles>

Oleanolic acid
Fig. 4 Chemical structures of neolignans (dieugenol, tetrahydrodieugenol, magnolol) and the triterpenoid oleanolic acid isolated from natural sources and discovered by in silico screening as being potential PPARy partial agonists.

\section{References}

1 Bailey CJ, Day C. Traditional plant medicines as treatments for diabetes. Diabetes Care 1989; 12: 553-564

2 Newman DJ, Cragg GM. Natural products as sources of new drugs over the 30 years from 1981 to 2010. J Nat Prod 2012; 75: 311-335

3 Poulsen LC, Siersbæk M, Mandrup S. PPARs: fatty acid sensors controlling metabolism. Semin Cell Dev Biol 2012; 23: 631-639

4 Rosen ED, Spiegelman BM. Molecular regulation of adipogenesis. Annu Rev Cell Dev Biol 2000; 16: 145-171

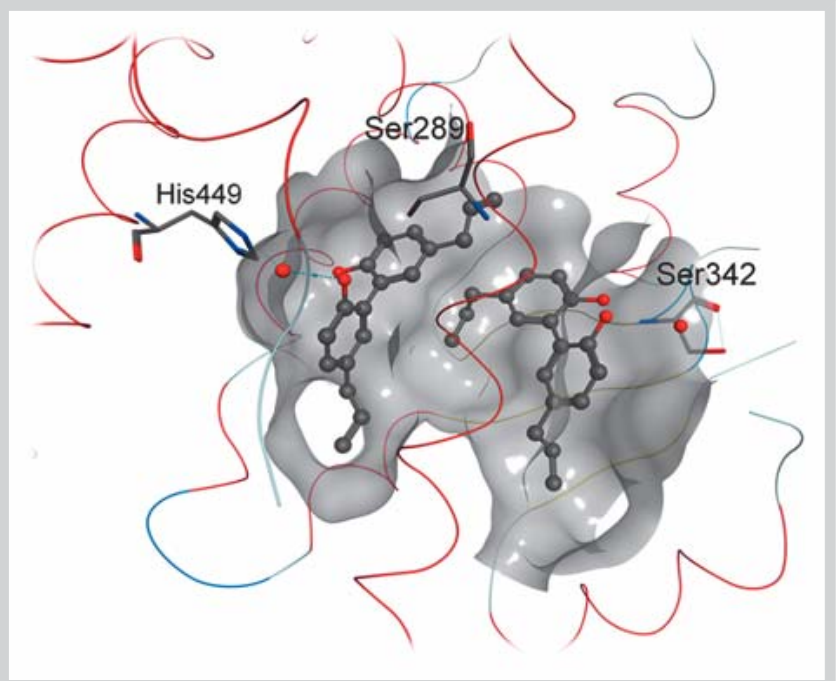

Fig. 5 Binding mode of magnolol to PPARy. Two magnolol molecules bound to the ligand-binding site of PPARY are shown in ball and stick depiction (PDB code 3R5N [74]). Key interacting residues are shown in stick mode. (Color figure available online only.)

5 Willson TM, Lambert MH, Kliewer SA. Peroxisome proliferator-activated receptor $\gamma$ and metabolic disease. Annu Rev Biochem 2001; 70: 341367

6 Choi JH, Banks AS, Estall JL, Kajimura S, Boström P, Laznik D, Ruas JL, Chalmers MJ, Kamenecka TM, Blüher M, Griffin PR, Spiegelman BM. Anti-diabetic drugs inhibit obesity-linked phosphorylation of PPAR $\gamma$ by Cdk5. Nature 2010; 466: 451-467

7 Shibuya A, Watanabe M, Fujita Y, Saigenji K, Kuwao S, Takahashi H, Takeuchi $H$. An autopsy case of troglitazone-induced fulminant hepatitis. Diabetes Care 1998; 21: 2140-2143

8 Berger JP, Petro AE, Macnaul KL, Kelly LJ, Zhang BB, Richards K, Elbrecht A, Johnson BA, Zhou G, Doebber TW, Biswas C, Parikh M, Sharma N, Tanen MR, Thompson GM, Ventre J, Adams AD, Mosley R, Surwit RS, Moller DE. Distinct properties and advantages of a novel peroxisome proliferator- 
activated protein $\gamma$ selective modulator. Mol Endocrinol 2003; 17: 662-676

9 Ekins S, Mestres J, Testa B. In silico pharmacology for drug discovery: methods for virtual ligand screening and profiling. $\mathrm{Br} \mathrm{J}$ Pharmacol 2007; 152: 9-20

10 Reddy AS, Pati SP, Kumar PP, Pradeep HN, Sastry GN. Virtual screening in drug discovery - a computational perspective. Curr Protein Pept Sci 2007; 8: 329-351

11 Ekins S, Mestres J, Testa B. In silico pharmacology for drug discovery: applications to targets and beyond. Br J Pharmacol 2007; 152: 21-37

12 Wolber G, Rollinger JM. Virtual screening and target fishing for natural products using 3D pharmacophores. In: Jacoby E, editor. Computational chemogenomics. Singapore: Pan Stanford Publishing; 2013: 117139

13 Rollinger JM, Wolber G. Computational approaches for the discovery of natural lead structures. In: Tringali $C$, editor. Bioactive compounds from natural sources, second edition. Natural products as lead compounds in drug discovery. Boca Raton, Florida, USA: CRC Press; 2012: 97-132

14 Ertl P, Schuffenhauer A. Cheminformatics analysis of natural products: lessons from nature inspiring the design of new drugs. Prog Drug Res 2008; 66: 217-235

15 Sarker SD, Nahar L. An introduction to natural products isolation. Methods Mol Biol; 2012; 864: 1-25

16 Schuster $D$, Wolber $G$. Identification of bioactive natural products by pharmacophore-based virtual screening. Curr Pharm Des 2010; 16: 1666-1681

17 Berman HM, Westbrook J, Feng Z, Gilliland G, Bhat TN, Weissig H, Shindyalov IN, Bourne PE. The protein data bank. Nucleic Acids Res 2000; 28: 235-242

18 Lewis SN, Bassaganya-Riera J, Bevan DR. Virtual screening as a technique for PPAR modulator discovery. PPAR Res 2010; 2010: 861238

19 Anderson AC, Wright DL. The design and docking of virtual compound libraries to structures of drug targets. Curr Comput-Aided Drug Des 2005; $1: 103-127$

20 Kitchen DB, Decornez H, Furr JR, Bajorath J. Docking and scoring in virtual screening for drug discovery: methods and applications. Nat Rev Drug Discov 2004; 3: 935-949

21 Halperin I, Ma B, Wolfson H, Nussinov R. Principles of docking: An overview of search algorithms and a guide to scoring functions. Proteins 2002; 47: 409-443

22 Perola E, Walters WP, Charifson PS. A detailed comparison of current docking and scoring methods on systems of pharmaceutical relevance. Proteins 2004; 56: 235-249

23 Wolber G, Langer T. LigandScout: 3-D pharmacophores derived from protein-bound ligands and their use as virtual screening filters. J Chem Inf Model 2005; 45: 160-169

24 Sousa SF, Ribeiro AJ, Coimbra JT, Neves RP, Martins SA, Moorthy NS, Fernandes PA, Ramos MJ. Protein-ligand docking in the new millennium a retrospective of 10 years in the field. Curr Med Chem 2013; 20: 2296-2314

25 Warren GL, Andrews CW, Capelli AM, Clarke B, LaLonde J, Lambert MH, Lindvall M, Nevins N, Semus SF, Senger S, Tedesco G, Wall ID, Woolven JM, Peishoff CE, Head MS. A critical assessment of docking programs and scoring functions. J Med Chem 2006; 49: 5912-5931

26 Hawkins PCD, Skillman AG, Nicholls A. Comparison of shape-matching and docking as virtual screening tools. J Med Chem 2007; 50: 74-82

27 Chen L, Morrow JK, Tran HT, Phatak SS, Du-Cuny L, Zhang S. From laptop to benchtop to bedside: structure-based drug design on protein targets. Curr Pharm Des 2012; 18: 1217-1239

28 Seidel T, Ibis G, Bendix F, Wolber G. Strategies for 3D pharmacophorebased virtual screening. Drug Discov Today Technol 2010; 7: e221e228

29 Venkatakrishnan AJ, Deupi X, Lebon G, Tate CG, Schertler GF, Babu MM. Molecular signatures of G-protein-coupled receptors. Nature 2013; 494: 185-194

30 Overington JP, Al-Lazikani B, Hopkins AL. How many drug targets are there? Nat Rev Drug Discov 2006; 5: 993-996

31 Wolber G, Dornhofer AA, Langer T. Efficient overlay of small organic molecules using 3D pharmacophores. J Comput Aided Mol Des 2006; 20: $773-788$

32 Krüger DM, Evers A. Comparison of structure- and ligand-based virtual screening protocols considering hit list complementarity and enrichment factors. ChemMedChem 2010; 5: 148-158
33 Klebe G. Virtual ligand screening: strategies, perspectives and limitations. Drug Discov Today 2006; 11: 580-594

34 Desvergne $B$, Wahli $W$. Peroxisome proliferator-activated receptors: nuclear control of metabolism. Endocr Rev 1999; 20: 649-688

35 Montanari R, Saccoccia F, Scotti E, Crestani M, Godio C, Gilardi F, Loiodice F, Fracchiolla G, Laghezza A, Tortorella P, Lavecchia A, Novellino E, Mazza F, Aschi M, Pochetti G. Crystal structure of the peroxisome proliferatoractivated receptor $\gamma$ (PPAR $\gamma$ ) ligand binding domain complexed with a novel partial agonist: a new region of the hydrophobic pocket could be exploited for drug design. J Med Chem 2008; 51: 7768-7776

36 Bruning JB, Chalmers MJ, Prasad S, Busby SA, Kamenecka TM, He Y, Nettles KW, Griffin PR. Partial agonists activate PPAR $\gamma$ using a helix 12 independent mechanism. Structure 2007; 15: 1258-1271

37 Goebel M, Wolber G, Markt P, Staels B, Unger T, Kintscher U, Gust R. Characterization of new PPAR $\gamma$ agonists: benzimidazole derivatives-importance of positions 5 and 6 , and computational studies on the binding mode. Bioorg Med Chem 2010; 18: 5885-5895

38 Markt P, Petersen RK, Flindt EN, Kristiansen K, Kirchmair J, Spitzer G, Distinto S, Schuster D, Wolber G, Laggner C, Langer T. Discovery of novel PPAR ligands by a virtual screening approach based on pharmacophore modeling, 3D shape, and electrostatic similarity screening. J Med Chem 2008; 51: 6303-6317

39 Guasch L, Sala E, Valls C, Blay M, Mulero M, Arola L, Pujadas G, GarciaVallve $S$. Structural insights for the design of new PPARgamma partial agonists with high binding affinity and low transactivation activity. J Comput Aided Mol Des 2011; 25: 717-728

40 Zoete V, Grosdidier A, Michielin O. Peroxisome proliferator-activated receptor structures: ligand specificity, molecular switch and interactions with regulators. Biochim Biophys Acta 2007; 1771: 915-925

41 Farce A, Renault N, Chavatte P. Structural insight into PPAR $\gamma$ ligands binding. Curr Med Chem 2009; 16: 1768-1789

42 Pochetti G, Godio C, Mitro N, Caruso D, Galmozzi A, Scurati S, Loiodice F, Fracchiolla G, Tortorella P, Laghezza A, Lavecchia A, Novellino E, Mazza F, Crestani $M$. Insights into the mechanism of partial agonism: crystal structures of the peroxisome proliferator-activated receptor $\gamma$ ligandbinding domain in the complex with two enantiomeric ligands. J Biol Chem 2007; 282: 17314-17324

43 Gelman L, Feige JN, Desvergne B. Molecular basis of selective PPAR modulation for the treatment of Type 2 diabetes. Biochim Biophys Acta 2007; 1771: 1094-1107

44 Lu IL, Huang CF, Peng YH, Lin YT, Hsieh HP, Chen CT, Lien TW, Lee HJ, Mahindroo N, Prakash E, Yueh A, Chen HY, Goparaju CMV, Chen X, Liao CC, Chao YS, Hsu JTA, Wu SY. Structure-based drug design of a novel family of PPAR y partial agonists: virtual screening, X-ray crystallography, and in vitro/in vivo biological activities. J Med Chem 2006; 49: 2703-2712

45 Choi JH, Banks AS, Kamenecka TM, Busby SA, Chalmers MJ, Kumar N, Kuruvilla DS, Shin Y, He Y, Bruning JB, Marciano DP, Cameron MD, Laznik D, Jurczak MJ, Schürer SC, Vidović D, Shulman GI, Spiegelman BM, Griffin PR. Antidiabetic actions of a non-agonist PPAR $\gamma$ ligand blocking Cdk5-mediated phosphorylation. Nature 2011; 477: 477-481

46 Hughes TS, Chalmers MJ, Novick S, Kuruvilla DS, Chang MR, Kamenecka TM, Rance M, Johnson BA, Burris TP, Griffin PR, Kojetin DJ. Ligand and receptor dynamics contribute to the mechanism of graded PPAR $\gamma$ agonism. Structure 2012; 20: 139-150

47 Hughes TS, Giri PK, Vera IMS, Marciano DP, Kuruvilla DS, Shin Y, Blayo AL, Kamenecka TM, Burris TP, Griffin PR, Kojetin DJ. An alternate binding site for PPAR $\gamma$ ligands. Nat Commun 2014; 5: 3571

48 Waku T, Shiraki T, Oyama T, Fujimoto Y, Maebara K, Kamiya N, Jingami $H$, Morikawa K. Structural insight into PPAR $\gamma$ activation through covalent modification with endogenous fatty acids. J Mol Biol 2009; 385: 188-199

49 Shiraki T, Kamiya N, Shiki S, Kodama TS, Kakizuka A, Jingami H. $\alpha, \beta$-Unsaturated ketone is a core moiety of natural ligands for covalent binding to peroxisome proliferator-activated receptor $\gamma$. J Biol Chem 2005; 280: 14145-14153

50 Marles RJ, Farnsworth NR. Antidiabetic plants and their active constituents. Phytomed 1995; 2: 137-189

51 Penumetcha $M$, Santanam N. Nutraceuticals as ligands of PPAR $\gamma$. PPAR Res 2012; 2012: 858352

52 Song MK, Roufogalis BD, Huang THW. Modulation of diabetic retinopathy pathophysiology by natural medicines through PPAR- $\gamma$-related pharmacology. Br J Pharmacol 2012; 165: 4-19

53 Huang THW, Kota BP, Razmovski V, Roufogalis BD. Herbal or natural medicines as modulators of peroxisome proliferator activated recep- 
tors and related nuclear receptors for therapy of metabolic syndrome. Basic Clin Pharmacol Toxicol 2005; 96: 3-14

54 Salam NK, Huang THW, Kota BP, Kim MS, Li Y, Hibbs DE. Novel PPARgamma agonists identified from a natural product library: a virtual screening, induced-fit docking and biological assay study. Chem Biol Drug Des 2008; 71: 57-70

55 Christensen KB, Petersen RK, Kristiansen K, Christensen LP. Identification of bioactive compounds from flowers of black elder (Sambucus nigra L.) that activate the human peroxisome proliferator-activated receptor (PPAR) $\gamma$. Phytother Res 2010; 24: S129-S132

56 Tanrikulu Y, Rau O, Schwarz O, Proschak E, Siems K, Muller-Kuhrt L, Schubert-Zsilavecz M, Schneider G. Structure-based pharmacophore screening for natural-product-derived PPAR $\gamma$ agonists. Chembiochem 2009; 10: 75-78

57 Rollinger JM, Haupt S, Stuppner H, Langer T. Combining ethnopharmacology and virtual screening for lead structure discovery: COX-inhibitors as application example. J Chem Inf Comput Sci 2004; 44: 480-488

58 Fakhrudin N, Ladurner A, Atanasov AG, Heiss EH, Baumgartner L, Markt P, Schuster D, Ellmerer EP, Wolber G, Rollinger JM, Stuppner H, Dirsch VM. Computer-aided discovery, validation, and mechanistic characterization of novel neolignan activators of peroxisome proliferator-activated receptor gamma. Mol Pharmacol 2010; 77: 559-566

59 Ehrman TM, Barlow DJ, Hylands PJ. Phytochemical databases of Chinese herbal constituents and bioactive plant compounds with known target specificities. J Chem Inf Model 2007; 47: 254-263

60 Irwin JJ, Sterling T, Mysinger MM, Bolstad ES, Coleman RG. ZINC: a free tool to discover chemistry for biology. J Chem Inf Model 2012; 52: $1757-1768$

61 Petersen RK, Christensen KB, Assimopoulou AN, Fretté X, Papageorgiou VP, Kristiansen K, Kouskoumvekaki I. Pharmacophore-driven identification of PPAR $\gamma$ agonists from natural sources. J Comput Aided Mol Des 2011; 25: 107-116

62 Guasch L, Sala E, Mulero M, Valls C, Salvadó MJ, Pujadas G, Garcia-Vallvé $S$. Identification of PPARgamma partial agonists of natural origin (II): in silico prediction in natural extracts with known antidiabetic activity. PLoS ONE 2013; 8: e55889

63 Guasch L, Sala E, Castell-Auvi A, Cedo L, Liedl KR, Wolber G, Muehlbacher M, Mulero M, Pinent M, Ardevol A, Valls C, Pujadas G, Garcia-Vallve S.
Identification of PPARgamma partial agonists of natural origin (I): development of a virtual screening procedure and in vitro validation. PLOS ONE 2012; 7: e50816

64 Goodsell DS, Olson AJ. Automated docking of substrates to proteins by simulated annealing. Proteins 1990; 8: 195-202

65 Ewing TJ, Makino S, Skillman AG, Kuntz ID. DOCK 4.0: search strategies for automated molecular docking of flexible molecule databases. J Comput Aided Mol Des 2001; 15: 411-428

66 Rarey M, Kramer B, Lengauer T, Klebe G. A fast flexible docking method using an incremental construction algorithm. J Mol Biol 1996; 261: 470-489

67 Halgren TA, Murphy RB, Friesner RA, Beard HS, Frye LL, Pollard WT, Banks JL. Glide: a new approach for rapid, accurate docking and scoring. 2. Enrichment factors in database screening. J Med Chem 2004; 47: $1750-1759$

68 Jones G, Willett P, Glen RC, Leach AR, Taylor R. Development and validation of a genetic algorithm for flexible docking. J Mol Biol 1997; 267: 727-748

69 Venkatachalam CM, Jiang X, Oldfield T, Waldman M. LigandFit: a novel method for the shape-directed rapid docking of ligands to protein active sites. J Mol Graph Model 2003; 21: 289-307

70 Meier R, Pippel M, Brandt F, Sippl W, Baldauf C. ParaDockS: a framework for molecular docking with population-based metaheuristics. J Chem Inf Model 2010; 50: 879-889

71 Jain AN. Surflex: fully automatic flexible molecular docking using a molecular similarity-based search engine. J Med Chem 2003; 46: 499-511

72 Mahindroo N, Peng YH, Lin CH, Tan UK, Prakash E, Lien TW, Lu IL, Lee HJ, Hsu JTA, Chen X, Liao CC, Lyu PC, Chao YS, Wu SY, Hsieh HP. Structural basis for the structure-activity relationships of peroxisome proliferator-activated receptor agonists. J Med Chem 2006; 49: 6421-6424

73 Jamali B, Bjørnsdottir I, Nordfang $O$, Hansen SH. Investigation of racemisation of the enantiomers of glitazone drug compounds at different $\mathrm{pH}$ using chiral HPLC and chiral CE. J Pharm Biomed Anal 2008; 46: 82-87

74 Zhang $H, X u X$, Chen L, Chen J, Hu L, Jiang H, Shen X. Molecular determinants of magnolol targeting both RXR $\alpha$ and PPARY. PLoS ONE 2011; 6: e28253 